\title{
Forgiveness, Hope, and Satisfaction With Life Among Senior High School Students Viewed From Family-related Characteristics in Indonesia
}

\author{
$1^{\text {st }}$ Amalia Rahmandani* \\ Faculty of Psychology \\ Diponegoro University \\ Semarang, Indonesia \\ a.rahmandani@live.undip.ac.id
}

\author{
$2^{\text {rd }}$ Yohanis Franz La Kahija \\ Faculty of Psychology \\ Diponegoro University \\ Semarang, Indonesia \\ franzlakahija@gmail.com
}

\begin{abstract}
This study aims to determine the differences in forgiveness, hope, and satisfaction with life based on familyrelated characteristics, namely birth order, the total number of siblings, parents' marriage status, housemate, parents' age category, parents' occupation nature, and parents' education, aside from general demographic characteristics, among Indonesian senior high school age students. Participants in this study were 909 students of a vocational high school in Semarang, Indonesia obtained through cluster random sampling technique $\left(\mathrm{M}_{\mathrm{Age}}=15.93 ; \mathrm{SD}_{\mathrm{Age}}=.909 ;\right.$ male=60.3\%; female $=39.7 \%$ ). Participants were asked to complete the identity including general demographic and family-related data, the Forgiveness Scale, the State Hope Scale, and the Satisfaction with Life Scale. Analyses were conducted using The Man-Whitney U and Kruskal Wallis Test. Spearman's rho and descriptive statistics were also used. The results of this study indicate that family-related characteristics have more contribution to differences in hope and satisfaction with life than forgiveness. Forgiveness was only distinguished by housemate and mother's age category. Hope was distinguished by the total number of siblings, parents' marriage status, housemate, father's occupation nature, and both parents' education. Satisfaction with life was distinguished by parents' marriage status, housemate, both parents' occupation nature, and father's education. This study also indicates how the dimensions of forgiveness and the subscales of state hope are specifically related and differentiated according to the familyrelated characteristics observed in this study. In addition, the results of this study indicate the importance of the role of gender differences, especially in the characteristics of fathers and mothers in terms of age, occupation, and education for the various differences of the variables examined in this study.
\end{abstract}

Keywords-positive psychology, family characteristic, adolescence, collectivistic country

\section{INTRODUCTION}

Family is considered as one of the ecological developmental assets that is important for positive youth development [1]. Ecological assets in the family, namely

This research was supported by the DIPA PNBP funding Fiscal Year 2019 of the Faculty of Psychology, Diponegoro University. perceived support by their primary caretakers (perceived parental support), are proven positively and significantly related to adolescents' positive cognitive judgment [2], positive affect [3], emotion regulation [4], and adjustment [5], [6]. Adaptive regulatory ability on the individual to their ecological environment, in this case including family, also contributes to increase the likelihood of positive development and thriving [1].

The childhood experiences regarding their families show long-term impact through adolescence as in [7]. Childhood experiences and perceived well-being are examined by taking into account various situations or characteristics related to the family. Reference [8] describes the results of the review of many studies that explain various pathways, or mechanisms, that may underlie the association between family structure and child well-being, including parental resources, parental mental health, parental relationship quality, parenting quality, father involvement, parental marriage status, parent(s) with whom the child lives, and family stability. Children from fragile families have different cognitive development and experience socio-emotional, behavioral, and health problems [8], [9].

In addition to developmental problems that may be experienced by children then last or strengthen in their teen years, the appraisals of the family also determine life choices in adolescents. Previous research found that the family's socioeconomic position affects the life course development and interrelationships of family members [10], appears to put stress on families in general, is associated with less satisfaction with several areas of family functioning, lower social support and quality of life than non-low-income families [11]. A study in Indonesia involving students from vocational high school found that students decided to take vocational education based on family conditions such as economic conditions as well as the nature of parents' work and income [12]. Students are expected to have greater opportunities to find work in competitive life so that they can immediately reduce the family's economic burden. The situation is then expected to shape economic and educational achievements and also competence as a parent and romantic partner during 
adulthood [10]. This may not be the solution because their teenage years might lead to situations that are not even better. The results of previous study in the same population explain that the perceived family distress among adolescents is positively related to depression, anxiety, and stress [13].

Forgiveness, hope, and satisfaction with life are positive psychological constructs that are interesting to be examined in relation to adolescents and family-related characteristics. Positive psychological constructs (e.g. hope, life satisfaction, self-worth, mindfulness, self-compassion, temperance, vitality, transcendence, gratitude) have been studied in adolescent populations and the results show that these constructs have meaningful relations with mental health and academic achievement [14], function as mediators in the pathway to emotional well-being [15] or relate to subjective well-being and happiness [16] even reduced materialism [17]. In contrast to adults, research on positive psychological attributes in adolescents may be challenging along with the dynamics of typical adolescent development, namely the increase in cognitive development maturity [18] and the presence of adolescent egocentrism such as imagery audience, personal fable, pseudo-stupidity, and apparent hypocrisy [19], [20].

Forgiveness in this study seems challenging, because it is a construct that is too abstract to be realized in adolescence and develops with age [21], [23]. Hope for adolescents is associated positively with self-esteem and optimism [24] and as a psychological strength, predicting depression and life satisfaction, and promoting emotional well-being [25]. Furthermore, life satisfaction is an important construct in the field of positive psychology because it is closely associated with happiness as well as a range of positive personal, behavioral, psychological, and social outcomes [26], [27].

The purpose of this study was to find out how the differences in family-related characteristics (i.e. birth order, the total number of siblings, parents' marriage status, housemate, parents' age category, parents' occupation nature, and parents' education), in addition to general demographic characteristics (i.e. sex, school grade, and ethnicity), determine the differences in forgiveness and its dimensions, hope and its subscales, and satisfaction with life among Indonesian high school students, spesifically vocational school.

\section{METHODS}

\section{A. Participants}

Participants who were involved in this study consisted of 909 students from a vocational high school in Semarang, Indonesia with the range of ages between 14 and 18 years $\left(\mathrm{M}_{\mathrm{Age}}=15.93 ; \mathrm{SD}_{\mathrm{Age}}=.909\right.$; male=60.3\%; female=39.7\% $)$. Vocational high school was chosen based on [12] that suggested that students' decision to to take vocational education that is determined by family conditions such as economic conditions as well as the nature of parents' work and income. Participants were obtained through cluster random sampling technique, namely by systematically randomizing classes representing each grade level (class $\mathrm{X}$ consisting of first-year students $=39.1 \%$; class XI consisting of second-year students $=39.4 \%$; class XII consisting of thirdyear students $=21.6 \%$ ). The number of students in class XII was smaller because half of the total students in that class was undergoing an internship for a semester.

\section{B. Measures}

Family-related Data. Participants' characteristics identified in the booklet were presented together with measurement scales, consisting of general demographic characteristics (i.e. sex, school grade, age, ethnicity) and family-related characteristics (i.e. birth order, the total number of siblings, parents' marriage status, housemate, parents' age, parents' occupation, and parents' education).

Forgiveness. The forgiveness scale used in this study was a scale compiled by researchers based on [28], which explains that forgiveness is a dialectical process through which people synthesize their prior assumptions and the reality of the transgression into a new understanding of the transgression, transgressors, transgression sequences, and, potentially, of themselves, other people, or the world. The scale consists of 40 items $(\alpha=.867)$, which are divided into 3 subscales: self-forgiveness, forgiveness of others, and forgiveness of situation. This is a Likert scale consisting of four response categories, namely Strongly Disagree, Disagree, Agree, and Strongly Agree. Scores on favorable items, sequentially scored $0,1,2$, and, 3; while scores on unfavorable items were scored $3,2,1$, and 0 . In this study, forgiveness scores were then grouped into a five-level category based on hypothetical norms, i.e. 'very low' $(x \leq 30)$, 'low' $(50 \geq x>30)$, 'moderate' $(70 \geq x>50)$, 'high' $(90 \geq x>70)$, and 'very high' $(x>90)$.

Hope. Hope in this study was measured using The State Hope Scale [29], that is a six-item scale that describes a cognitive set based on a reciprocally-derived sense of successful agency (goal-directed determination) and pathways (planning to meet goals). Agency taps the individual's perceived capacity for initiating and maintaining the actions necessary to reach a goal. While pathways taps the perceived ability to generate routes to one's goals [29]. This scale was adapted into Indonesian language and tested in this study population $(\alpha=.701)$. Respondents were asked to take a few moments to focus on what was going on in their lives and selected the number that best described how they thought about themselves and put that number in the blank provided (on an 8-point scale, with 1 = Definitely False, 2 = Mostly False, $3=$ Somewhat False, $4=$ Slightly False, $5=$ Slightly True, $6=$ Somewhat True, $7=$ Mostly True, and $8=$ Definitely True). The evennumbered items are agency, and the odd-numbered items are pathways. Subscale scores for agency or pathways are derived by adding the three even- and odd-numbered items, and the total State Hope Scale score is the sum of all six items. In this study, the state hope scores were then grouped into a five-level category based on hypothetical norms, i.e. 'very low' $(x<18)$, 'low' $(24>x \geq 18)$, 'moderate' $(31>x \geq 24)$, 'high' (38>x $\geq 31)$, and 'very high' $(\mathrm{x} \geq 38)$.

Satisfaction with Life. Life satisfaction was measured using The Satisfaction with Life Scale (SWLS) as in [30]. Person's global judgment of life satisfaction is assessed by this a five-item scale of SWLS. It is theoretically predicted to depend on a comparison of life circumstances to one's standards [31]. The psychometric properties of this scale among adolescents sample had been examined previously [32]. This scale was adapted into Indonesian language and tested in this study population $(\alpha=.733)$. Participants were asked to choose one of the seven-point scale that indicated participants' agreement of each item, namely $1=$ strongly disagree, 2 = disagree, $3=$ slightly disagree, $4=$ neither 
agree nor disagree, $5=$ slightly agree, $6=$ agree, and $7=$ strongly agree. The total number of all scores is the final result of the scale. In this study, satisfaction with life scores were then grouped into a five-level category based on hypothetical norms, i.e. 'very low' $(x<13)$, 'low' $(18>x \geq 13)$, 'moderate' $(23>x \geq 18)$, 'high' $(28>x \geq 23)$, and 'very high' $(\mathrm{x} \geq 28)$.

\section{Procedure}

Researchers conducted a literature study before submitting a research permit letter to involve students in a vocational school where the study was planned. Participants were selected through cluster random sampling by taking into account the proportions of students in classes X, XI, and XII. Researchers met the ethical standards by asking for approval from the participants to engage in data collection activities voluntarily, and then signed the informed consent form voluntarily. The booklet was responded manually as soon as it was distributed and completed between 15 and 30 minutes.

\section{Data Analysis}

The responses from the participants were then scored. Some participants' characteristics were grouped and then coded as shown in Table 1 . The results of normality test that showed that data were not normally distributed were considered for using non-parametric inferential statistics to answer the objectives of this study, namely The ManWhitney U and Kruskal Wallis Test. Descriptive statistic and correlational examination using Spearman's rho were also carried out to get a more comprehensive picture of the results.

\section{RESULT}

\section{A. Demographic Characteristics of Participants and} Descriptive Statistics of the Variables

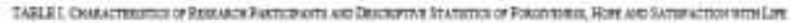

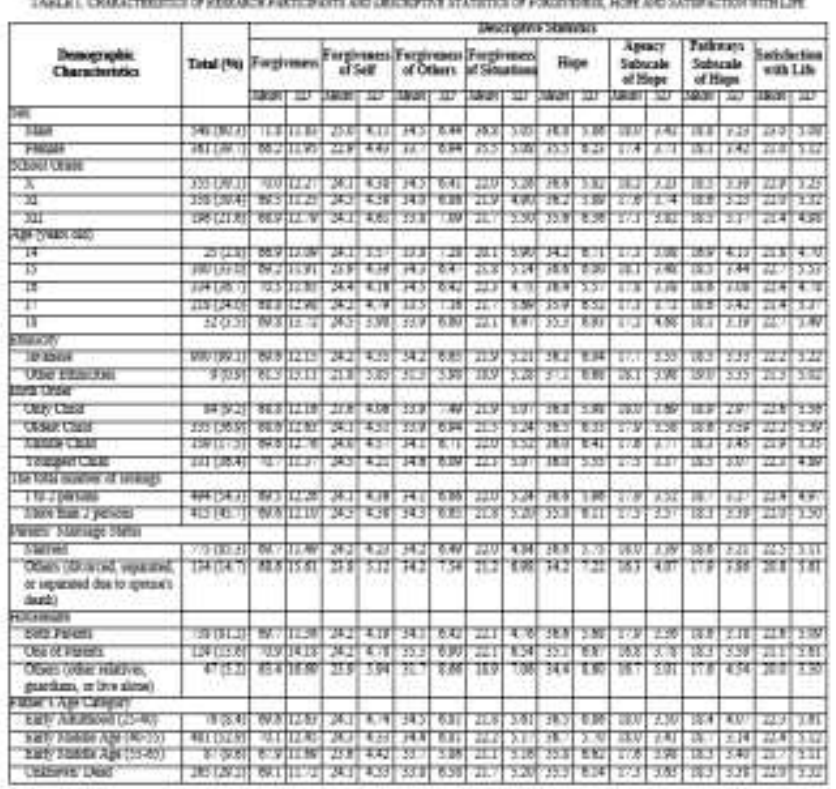

Table 1 shows the number and percentage of 909 participants based on the characteristics that were identified in this study, i.e. sex, school grade, age, ethnicity, birth order, the total number of siblings, parents' marriage status, housemate, parents' age category, parents' occupation nature, and parents' education. Table 1 also presents descriptive statistic (mean and standard deviation) based on each categorization of characteristics on each positive psychological variable, including forgiveness and its dimensions, hope and its subscales, and satisfaction with life. The difference of each variable's average according to demographic characteristics can be used as a reference when the test of comparative inferential statistics (Table 2) is significantly proven. For example in terms of sex, male

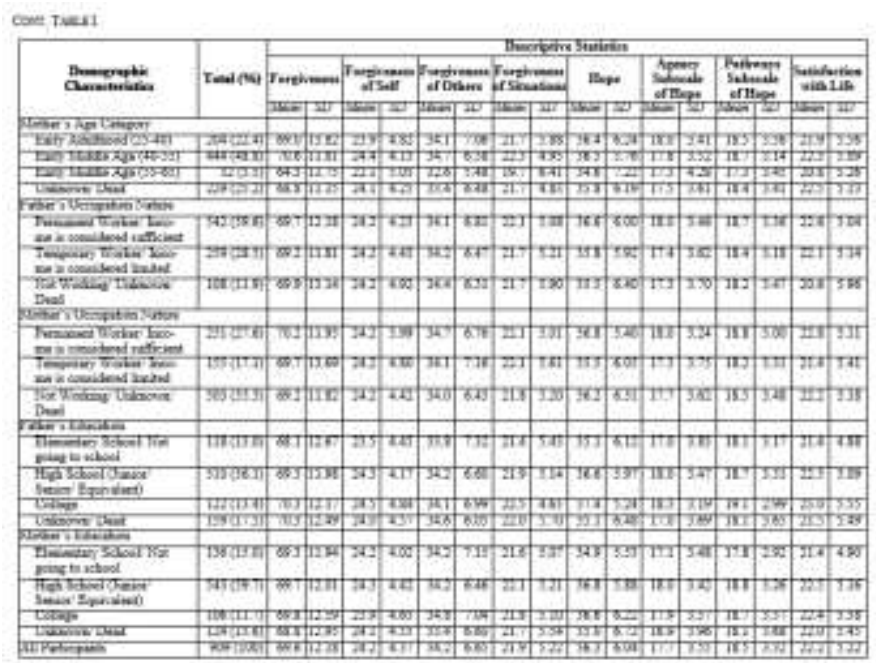

teenagers had a higher level than female teenagers in terms of forgiveness, hope, and satisfaction with life. Likewise, in terms of parental marital status, adolescents with married and complete parents had higher levels of forgiveness, hope, and satisfaction with life, compared to adolescents with other parental statuses (divorced, separated, or separated due to death). Differences in the results of the mean rank of the Man-Whitney U Test and the Kruskal Wallis Test which are not presented in this paper were also taken into consideration.

\section{B. Score Distributions of Each Variable into Categories}

Data distribution of positive psychological variables based on score categorization shows that, in a dummy manner, the percentage trend of respondents in the distribution of forgiveness (and its dimensions) and satisfaction with life scores seem more like normal distribution than hope scores distribution (and its subscales). The majority of respondents have forgiveness in the medium and high categories with a percentage ranging from $38.4 \%$ to $48.1 \%$. Likewise in the satisfaction with life variable, the majority of respondents were in the moderate category $(36.0 \%)$ followed by the high category $(31.5 \%)$.

In contrast to other positive psychological variables, the percentage of hope both in general and according to each subscale (agency and pathways) shows that sequentially from highest to lowest are in the very high category $(45.8 \%$ $53.6 \%)$, high (28.7\%-38.2\%), moderate (13.3\%-17.3\%), low $(2.1 \%-4.0 \%)$, and lastly low $(0.6 \%-1.3 \%)$. The trend of progressive increase in the variables of hope and its subscales from very low to very high categories is not found in the variables of forgiveness (and its dimensions) and satisfaction with life. This distinctive distribution needs attention because it might have implications for the next statistical test, and whether this is a unique characteristic of adolescents. 


\section{Correlations between Demographic Characteristics and Positive Psychological Variables}

The results of Spearman's rho statistical analysis used to test the correlation between demographic characteristics and positive psychological variables show a fairly varied correlation. Positive psychological variables are most significantly associated with sex compared to other characteristics at .01 level $\left(\mathrm{r}_{\mathrm{xy}}\right.$ ranged from .068 to the highest correlation of all, i.e. .253). This shows the extent of the contribution of sex differences to the variable score variations.

In addition, hope and its agency subscale, followed by satisfaction with life, show the most significant correlation with participant characteristics. This is in contrast to forgiveness, its dimensions, and the pathways subscale of hope, which have far less significant correlation with participant characteristics. These show how variations in characteristics, as identified in this study, predict/contribute more to hope, its agency subscale, and satisfaction with life, compared to forgiveness, its dimensions, and pathways subscale of hope.

\section{Differences in Positive Psychological Variables Based on Categorical Characteristics}

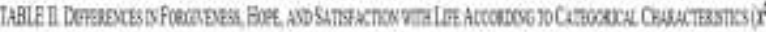

\begin{tabular}{|c|c|c|c|c|c|c|c|c|}
\hline Groping Vetith & Fengreans & $\begin{array}{c}\text { Fonginen } \\
\text { dStll }\end{array}$ & $\begin{array}{l}\text { forgineso } \\
\text { doters }\end{array}$ & $\begin{array}{l}\text { Poppines } \\
\text { wSinatives }\end{array}$ & Hip: & $\begin{array}{l}\text { lgars } \\
\text { Silscit }\end{array}$ & $\begin{array}{l}\text { Fitrems } \\
\text { Satsede }\end{array}$ & $\begin{array}{l}\text { Safsiative } \\
\text { sithLit }\end{array}$ \\
\hline $1.5 \mathrm{at}$ & $+4.513^{21}$ & $54.5 \%$ & $2 \times 2$ & $5169^{\circ}$ & 6ू" & 428 & 10 sen" & 32724 \\
\hline 2.ScasilGait & 183 & 7y & 94 & 1.91 & 212 & $1590^{\circ}$ & 36 & II.340 \\
\hline IEtexty & $35 \%$ & $|| A \mid$, & $2 \sqrt{60}$ & 335 & 147 & A2 & 31 & 357 \\
\hline 1. 3ott Cota & 469 & 3.166 & 247 & 270 & $3,9,9$ & 4610 & $29 !$ & 143 \\
\hline 5. Fund numer of wing & 125 & 312 & 100 & .07 & $50000^{\circ}$ & $57 x^{4}$ & 321 & IAH \\
\hline 6. Puent Ylanges Stem & 335 & .107 & 50 & $\pi 6$ & $119 \pi^{\prime \prime}$ & $20.63^{4}$ & 249 & $878^{n}$ \\
\hline Fourais & $8.7 \%$ & 10. & 6.112 & 9234 & $6 \%$ & $10222^{4}$ & 1,09 & स655" \\
\hline 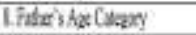 & $2(M)$ & SW! & 1356 & 3,006 & 1199 & .73 & 139 & 100 \\
\hline Inteifectay & $715 \%$ & $6055^{\circ}$ & 135 & 3.88 & 215 & 56 & $61^{10}$ & 2141 \\
\hline MFrtar's0uaptits Ktax & 115 & 12 & Lका & $5+$ & $7300^{\circ}$ & 6 t5 & t504 & $965 \%$ \\
\hline 11. Nader iQvopition Kint & LII & .18 & 120 & 30 & IM & 3.35 & 2811 & 739 \\
\hline 12Fintris Eteten & 123 & 4951 & 315 & 1.17 & 1057 & 5239 & 7390 & 7114 \\
\hline 13. Notar's Btrifin & उश) & 367 & 39 & 196 & $159)^{\prime \prime}$ & हुज & $\left.138\right|^{\prime \prime}$ & 567 \\
\hline
\end{tabular}

The Man-Whitney U Test and the Kruskal Wallis Test were conducted to see how the differences in positive psychological variables were based on categorical characteristics (Table 2). Among categorical general demographic characteristics (sex, school grade, ethnicity), the score differences on each positive psychological variable score are the most prominent positive psychological variables which are strikingly (at most) determined by sex. Forgiveness, self-forgiveness, forgiveness of situations, hope and its subscales, and satisfaction with life in male participants are significantly higher than those in female, but this does not apply to the dimension of forgiveness of others $\left(\chi^{2}=2.192 ; p=.139\right)$. There are differences in agency subscale of hope and satisfaction with life based on school grades; while the ethnicity does not contribute to differences in all variables. The last result can be ignored due to the differences in the number of participants between ethnicities.

Compared to hope and satisfaction with life, the differences in forgiveness and its dimensions are less determined by the family-related characteristics identified in this study. Among all family-related characteristics, only housemate and mother's age category play a part in the difference. Differences in housemate(s) distinguish forgiveness, forgiveness of others, and forgiveness of situations. Supported by descriptive statistics in Table 1 (and also the mean rank resulting from the Kruskal Wallis Test), adolescents who live with one of parents show the highest forgiveness, forgiveness of others, and forgiveness of situations; followed by those who live with their both parents. Adolescents who live with people other than their parents (other relatives, guardians, or live alone) show the lowest score. Furthermore, differences in the mother's age category distinguish significantly the score of forgiveness in general and self-forgiveness. Differences in scores of forgiveness of others and situations also show a similar trend but not significant. Adolescents whose mothers are in early middle age have the highest scores of forgiveness in general and self-forgiveness, followed by those whose mothers are in early adulthood. Adolescents whose mothers are in late middle age have the lowest scores of forgiveness in general and self-forgiveness.

In contrast to forgiveness and its dimensions, differences in the score of hope (and its subscales) and the satisfaction with life variables are more determined by the family-related characteristics identified in this study. There are significant differences in the hope and its agency subscale scores based on the total number of siblings, parents' marriage status, housemate, father's occupation nature, and parents' education. Significant differences in the pathways subscale of hope are determined by the mother's age category and parents' education. That the agency subscale is more determined by various family-related characteristics compared to the pathways subscale needs to be highlighted. While significant differences in satisfaction with life are determined by parents' marriage status, housemate, parents' occupation nature, and father's education. Adolescents with less than two siblings have higher hope and goal-directed energy (agency subscale) than those with more than two total number of siblings. Adolescents with married parental status have higher hope, goal-directed energy, and satisfaction with life than those with other parents' marital status (divorced, separated, or separated due to spouse's death). Adolescents who live with both parents had the highest hope, goal- directed energy, and satisfaction with life, followed by those who live with single parent, while those who live with others (other relatives, guardians, or live alone) have the lowest score. In line with differences in forgiveness based on mother's age category, the pathways subscale of hope (planning to meet goals) is also significantly different, namely the highest scores are in adolescents whose mothers are in the early middle age, followed by those whose mothers are in early adulthood, and the lowest scores are in those whose mothers are in late middle age.

In relation to parents' occupation, differences in father's occupation nature give more influence to differences in hope and its agency subscale scores, where the highest scores are shown by adolescents whose fathers are permanent workers or have sufficient income, followed by adolescents whose fathers are non-permanent workers or have income which is considered limited, and the lowest is shown by adolescents whose fathers do not work or have died or whose jobs are unknown. While differences in score of satisfaction with life variable are determined by differences in parents' occupation nature, both father $(p<.01)$ and mother $(p<.05)$. Father or mother eith 
permanent job or enough income has children with highest life satisfaction score compared to the others. However, in contrast to adolescents whose fathers are non- permanent workers (or have limited income) have higher life satisfaction than those whose fathers are unemployed (or have died or whose job are unknown), adolescents whose mothers are non-permanent workers (or limited income) actually have lower life satisfaction than those whose mothers are unemployed (or have died or whose job are unknown). Finally, parents' occupation nature does not contribute to differences in pathways subscale of hope.

The last family-related characteristic is parents' education. Although there are different trends, the differences between father's education and mother's education also determine differences in hope and its subscales. Adolescents whose fathers are university graduates had the highest hope and its subscales scores, then declined and differed significantly in adolescents whose fathers are high school graduates. The lowest scores are shown by adolescents whose fathers are not educated (or have an elementary school education). Conversely, the trend of differences in hope and its subscales scores based on mother's education, the highest score is shown by adolescents whose mothers are high school graduates, then decreases and is significantly different in adolescents whose mothers are university graduates. The lowest score is shown by adolescents whose mothers are not educated (or have an elementary school education). In terms of satisfaction with life, differences in father's education determine differences in satisfaction with life scores compared to mother's education.

\section{IV.DISCUSSION}

To begin the discussion, the results of this study show that the progressive increasing trend in the hope variable and its subscales from very low to very high categories may indicate characteristics commonly shared in adolescents, namely the development in cognitive abilities along with brain development so cognitive functions become more mature [18], and the presence of adolescent egocentrism in the form of personal fable, where adolescents see themselves as unique and invincible, which reflects an incomplete understanding of the self [19]. The existence of bias optimism as a result of personal fable [33] seems to be related to hope. The results of meta-analysis show the relationship between optimism and hope [34].

Interesting results are obtained when family-related characteristics correlate with and differentiate agency subscale of hope (goal-directed energy) more than pathways subscale of hope (planning to meet goals). The striking difference of implications in the two subscales of hope has been studied previously [35]. Answering the results of the current study, the development of the prefrontal cortex in adolescents develops much more slowly than the limbic system, which is the seat of emotions and where rewards experienced [36]. This condition results in that the experience of very strong emotions is not sufficiently supported by the development of the prefrontal cortex which is expected to help control the passion. 'Decisive' decision making can occur impulsively, but it is not accompanied by careful planning for the achievement of goals. This is also in line with the apparent hypocrisy characteristic of adolescents that is the ability to conceive ideals and the inability to relate ideals to behavior [20]. Elkind's view on adolescent egocentrism is still used in recent literature [37], [38].
Reference [39] states that adolescent egocentrism even persists during younger adult (19-30 years).

Family-related characteristics relate to and differentiate hope and life satisfaction more than forgiveness. This shows that family attributes are valued by adolescents as promising (or not) for present and future life. Previous findings support these results, where family attributes such as those indicating socioeconomic status are related to adolescent life satisfaction [40] for example through increased self-esteem [41], aspirations [42], hope [43], and mental health in general [44], or as parental marital status is related to hope [45]. Forgiveness is less related and distinguished by familyrelated characteristics because forgiveness is a construct that is too abstract to be realized in adolescence and develops with age [21], [23]. One interesting result about how housemate(s) distinguish(es) forgiveness in general (higher forgiveness in adolescents living with one parent than both parents, and lowest in those who live with others) might indicate the important role of adversity experiences in forgiveness development [46] or the influence of other diverse situations [47]. However, further research needs to be carried out.

In some results, the characteristics of fathers are indicated to have influences (such as occupation nature for hope, and education background for life satisfaction). These seem to be related to how adolescents perceive the presence and status of father more supportive to their attainment than mother as in [48]. Adolescents whose fathers are nonpermanent workers have higher life satisfaction than those whose fathers are unemployed, whereas adolescents whose mothers are non-permanent workers have lower life satisfaction than those whose mothers are unemployed. This might be due to the role of gender differences in local cultures where unemployed mothers are more common than unemployed fathers, or the role of mothers as housewives is quite more desirable. Mothers are more expected to be present for the development of emotional regulation of children and adolescents [4]. Similar to these results, the other results of this study also explain that males have significantly higher levels of life expectancy and satisfaction, even forgiveness, than females.

\section{CONCLUSION}

Adolescent's characteristics in terms of cognitive development that is characterized by adolescent egocentrism and emotional development seem to have a unique impact on the positive psychological constructs in the current study. However, this study opens the opportunity for more family- related characteristics to be studied and identified more accurately. How family-related characteristics relate to and differentiate forgiveness, hope, and life satisfaction opens research opportunity by involving more positive psychological constructs. Similar studies on groups of subjects with different developmental periods, diverse cultural characteristics, need to be done to prove the arguments regarding the results of current study.

\section{REFERENCES}

[1] R. M. Lerner, A. von Eye, S. Lewin-Bizan, and E. P. Bowers, "Special issue introduction: The meaning and measurement of thriving: A view of the issues," J. Youth Adolesc., vol. 39, no. 7, pp. 707-719, 2010

[2] E. Oberle, K. A. Schonert-Reichl, and B. D. Zumbo, "Life satisfaction in early adolescence: Personal, neighborhood, school, family, and peer influences," J. Youth Adolesc., vol. 40, no. 7, pp. 
889-901, 2011.

[3] L. F. Katz et al., "Parental emotion socialization in clinically depressed adolescents: Enhancing and dampening positive affect,' J. Abnorm. Child Psychol., vol. 42, no. 2, pp. 205-215, 2014.

[4] E. Bariola, E. K. Hughes, and E. Gullone, "Relationships between parent and child emotion regulation strategy use: A brief report," $J$. Child Fam. Stud., vol. 21, no. 3, pp. 443-448, 2012.

[5] L. Cui, A. S. Morris, M. M. Criss, B. J. Houltberg, and J. S. Silk, "Parental psychological control and adolescent adjustment: The role of adolescent emotion regulation," Parenting, vol. 14, no. 1, pp. 47-67, 2014

[6] M. Kerr, H. Stattin, and M. Özdemir, "Perceived parenting style and adolescent adjustment: Revisiting directions of effects and the role of parental knowledge," Dev. Psychol., vol. 48, no. 6, pp. 1540-1553, 2012

[7] C. Sousa et al., "Longitudinal study on the effects of child abuse and children's exposure to domestic violence, parent-child attachments, and antisocial behavior in adolescence," J. Interpers. Violence, vol. 26, no. 1, pp. 111-136,2011

[8] J. Waldfogel, T. Craigie, and J. Brooks-gunn, "Fragile families and child wellbeing," Futur. Child., vol. 20, no. 2, pp. 87-112, 2010.

[9] T. Craigie, J. Brooks-Gunn, and J. Waldfogel, "Family structure, family stability and early child wellbeing," NJ, 2010.

[10] R. D. Conger, K. J. Conger, and M. J. Martin, "Socioeconomic status, family processes, and individual development," J. Marriage Fam., vol. 72, no. 3, pp. 685-704, 2010.

[11] A. K. Mansfield, J. A. Dealy, and G. I. Keitner, "Family functioning and income: Does low-income status impact family functioning?," Fam. J., vol. 21, no. 3, pp. 297-305, 2013.

[12] S. Maryati, "Factors that influence community preferences in choosing a state vocational high school in Semarang city (Faktorfaktor yang mempengaruhi preferensi masyarakat dalam memilih sekolah menengah kejuruan negeri (smkn) di kota Semarang)," Diponegoro University, 2009.

[13] A. Rahmandani, Y. F. La Kahija, H. Sakti, and L. N. Ardhiani, "Exploring perceived family distress and negative emotional states among indonesian adolescents," Int. J. Psychosoc. Rehabil., vol. 24, no. 1, pp. 1407-1419, 2020.

[14] S. C. Marques, J. L. Pais-Ribeiro, and S. J. Lopez, "The role of positive psychology constructs in predicting mental health and academic achievement in children and adolescents: A two-year longitudinal study," J. Happiness Stud., vol. 12, no. 6, pp. 1049$1062,2011$.

[15] K. Bluth and P. W. Blanton, "Mindfulness and self-compassion: Exploring pathways to adolescent emotional well-being," J. Child Fam. Stud., vol. 23, no. 7, pp. 1298-1309, 2013.

[16] E. Toner, N. Haslam, J. Robinson, and P. Williams, "Character strengths and wellbeing in adolescence: Structure and correlates of the Values in Action Inventory of Strengths for Children," Pers. Individ. Dif., vol. 52, no. 5, pp. 637-642, 2012.

[17] J. J. Froh, R. A. Emmons, N. A. Card, G. Bono, and J. A. Wilson, "Gratitude and the reduced costs of materialism in adolescents," $J$ Happiness Stud., vol. 12, no. 2, pp. 289-302, 2011.

[18] A. Caballero, R. Granberg, and K. Y. Tseng, "Mechanisms contributing to prefrontal cortex maturation during adolescence," Neurosci. Biobehav. Rev., vol. 70, pp. 4-12, 2016.

[19] D. Elkind, "Egocentrism in adolescence," Child Dev., vol. 38, no. 4, 1967.

[20] D. Elkind, Development of the Child. New York, NY: Wiley, 1978.

[21] R. D. Enright, M. J. D. Santos, and R. Al-Mabuk, "The adolescent as forgiver," J. Adolesc., vol. 12, no. 1, pp. 95-110, 1989.

[22] M. J. Subkoviak et al., "Measuring interpersonal forgiveness in late adolescence and middle adulthood," J. Adolesc., vol. 18, no. 6, pp. 641-655, 1995.

[23] M. Girard and E. Mullet, "Forgiveness in adolescents, young, middle-aged, and older adults," J. Adult Dev., vol. 4, no. 4, pp. 209-220, 1997.

[24] Y. Ling, E. S. Huebner, J. Liu, W. Liu, J. Zhang, and J. Xiao, "The origins of hope in adolescence: A test of a social-cognitive model," Pers. Individ. Dif., vol. 87, pp. 307-311, 2015.

[25] D. G. Lagacé-séguin and M. R. L. d' Entremont, "A scientific exploration of positive psychology in adolescence: The role of hope as a buffer against the influences of psychosocial negativities," Int. J. Adolesc. Youth, vol. 16, no. 1, pp. 69-95,
2010.

[26] E. Diener, "Subjective well-being," in The science of well-being. The collected work of Ed Diener, Social Indicators Research Series 37.

[27] S. Lyubomirsky, L. King, and E. Diener, "The benefits of frequent positive affect: Does happiness lead to success?," Psychol. Bull. vol. 131, pp. 803-855, 2005.

[28] L. Y. Thompson et al., "Dispositional forgiveness of self, others, and situations," J. Pers., vol. 73, no. 2, pp. 313-360, 2005.

[29] C. R. Snyder, S. C. Sympson, F. C. Ybasco, T. F. Borders, M. A. Babyak, and R. L. Higgins, "Development and validation of the State Hope Scale," J. Pers. Soc. Psychol., vol. 70, no. 2, pp. 321$335,1996$.

[30] E. Diener et al., "The Satisfaction With Life Scale," J. Pers. Assess., vol. 49, no. 1, pp. 71-75, 1985.

[31] W. Pavot and E. Diener, "Review of the Satisfaction With Life Scale," Soc. Indic. Res. Ser., pp. 101-117, 2009.

[32] F. Neto, "The Satisfaction with Life Scale: Psychometrics properties in an adolescent sample," J. Youth Adolesc., vol. 22, no. 2, pp. 125-134, 1993.

[33] M. Masiero, C. Lucchiari, and G. Pravettoni, "Personal Fable: Optimistic Bias in Cigarette Smokers," vol. 4, no. 1, pp. 1-7, 2015.

[34] G. M. Alarcon, N. A. Bowling, and S. Khazon, "Great expectations : A meta-analytic examination of optimism and hope," Pers. Individ. Dif., vol. 54, no. 7, pp. 821-827, 2013.

[35] S. C. Roesch, K. M. Duangado, A. A. Vaughn, A. A. Aldridge, and F. Villodas, "Dispositional hope and the propensity to cope: A daily diary assessment of minority adolescents," Cult. Divers. Ethn. Minor. Psychol., vol. 16, no. 2, pp. 191-198, 2010.

[36] S. Blakemore and K. L. Mills, "Is Adolescence a sensitive period for sociocultural processing?," Annu. Rev. Psychol., vol. 65, no. 1, pp. 187-207, 2014

[37] J. W. Santrock, Adolescence, sixteenth edition. New York, NY: McGraw-Hill Education, 2016.

[38] D. E. Papalia, S. W. Olds, and F. R. D., Human development 10th ed, 10th ed. New York: McGraw-Hill Edication, 2009.

[39] K. D. Frankenberger, "Adolescent egocentrism: A comparison among adolescents and adults," J. Adolesc., vol. 23, no. 3, pp. 343$354,2000$.

[40] R. Bannink, A. Pearce, and S. Hope, "Family income and young adolescents' perceived social position: associations with selfesteem and life satisfaction in the UK Millennium Cohort Study," Arch. Dis. Child., vol. 101, no. 10, pp. 917-921, 2016.

[41] W. Chen, G. Niu, D. Zhang, C. Fan, Y. Tian, and Z. Zhou, "Socioeconomic status and life satisfaction in Chinese adolescents: Analysis of self-esteem as a mediator and optimism as a moderator," Pers. Individ. Dif., vol. 95, pp. 105-109, 2016.

[42] K. Marjoribanks, "Occupational status, family environments, and adolescents' aspirations: The Laosa model," J. Educ. Psychol., vol. 76, no. 4, pp. 690-700, 1984.

[43] X. Yin, Z. Li, Y. Yuan, and Z. Wang, "Developmental trajectory of hope among late-adolescents: Population heterogeneity and the impact of gender and family socioeconomic status," J. Adolesc., vol. 72, no. June 2018, pp. 124-131, 2019.

[44] F. Reiss, "Socioeconomic inequalities and mental health problems in children and adolescents: A systematic review,"Soc. Sci. Med., vol. 90, pp. 24-31, 2013

[45] W. H. Chui and M. Y. H. Wong, "Association between parents' marital status and the development of purpose, hope, and selfesteem in adolescents in Hong Kong," J. Fam. Issues, vol. 38, no. 6, pp. 1-19, 2015.

[46] M. Plews-Ogan, M. Ardelt, and J. Owens, "Growth through adversity: Exploring associations between internal strengths, posttraumatic growth, and wisdom," J. Value Inq., vol. 53, pp. 371-391, 2018

[47] A. Booth, M. E. Scott, and V. King, "Father residence and adolescent problem behavior: Are youth always better off in twoparent families?," J. Fam. Issues, vol. 31, no. 5, pp. 585-605, 2010.

[48] M. Bacikova-sleskova, A. M. Geckova, J. P. van Dijk, J. W. Groothoff, and S. A. Reijneveld, "Parental support and adolescents' health in the context of parental employment status," J. Adolesc., vol. 34, no. 1, pp. 141-149, 2011. 